\title{
WestVirginiaUniversity
}

THE RESEARCH REPOSITORY @ WVU

Graduate Theses, Dissertations, and Problem Reports

2006

\section{A cross-cultural design pattern: Chinese modern design}

Feifei Fan

West Virginia University

Follow this and additional works at: https://researchrepository.wvu.edu/etd

\section{Recommended Citation}

Fan, Feifei, "A cross-cultural design pattern: Chinese modern design" (2006). Graduate Theses, Dissertations, and Problem Reports. 748.

https://researchrepository.wvu.edu/etd/748

This Thesis is protected by copyright and/or related rights. It has been brought to you by the The Research Repository @ WVU with permission from the rights-holder(s). You are free to use this Thesis in any way that is permitted by the copyright and related rights legislation that applies to your use. For other uses you must obtain permission from the rights-holder(s) directly, unless additional rights are indicated by a Creative Commons license in the record and/ or on the work itself. This Thesis has been accepted for inclusion in WVU Graduate Theses, Dissertations, and Problem Reports collection by an authorized administrator of The Research Repository @ WVU. For more information, please contact researchrepository@mail.wvu.edu. 


\title{
A Cross-cultural Design Pattern: \\ Chinese Modern Design
}

\author{
Feifei Fan
}

Thesis submitted to the

College of Creative Arts

at West Virginia University

in partial fulfillment of the requirements

for the degree of

\author{
Master of Arts \\ in \\ Visual Art
}
Eve Faulkes, M.F.A., Chair
Heidi Specht, M.F.A
Juan Giraldo, M.F.A
Paul Krainak, M.F.A

Department of Graphic Design

Morgantown, West Virginia

2006

Keywords: Graphic Design, Cross-cultural Design, Modern Chinese Design

Copyright 2006 Feifei Fan 


\title{
Abstract \\ A Cross-cultural Design Pattern: Modern Chinese Design
}

\author{
Feifei Fan \\ Chinese graphic designers are gaining more visibility \\ and earn awards in various international poster \\ competitions, shaping a new visual frontier in Chinese \\ graphic design. These successes are based on their \\ special cross-cultural design principle, which combines \\ Chinese traditional culture with the imported Western \\ modern design theory. In this paper, Modern Chinese \\ design history, development and characteristics are \\ reviewed. Meanwhile, some existing principles are \\ demonstrated and something new is experimented \\ through the series posters design.
}


To my talented wife, Dr. Jianxia Cui, whose love and supports encourage me to chase my dream;

To my beautiful daughter, Margaret Heyi Fan, who has inspired me to finish this project. 
I wish to give my thanks to Professor Cliff Harvey, who took me to this amazing field, and always understands and supports me like a father. 


\section{Table of Contents}



Shanghai Style: Origin of Modern Chinese Design................................2

Hong Kong Period: Three Swordsmen......................................4

1978: The Waken Lion................................................... 8

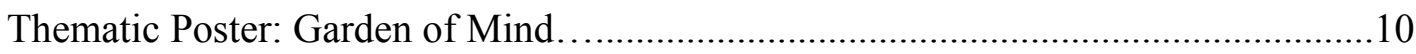

ABC Issue: The Confusion as Marginal Men …................................13

My Solution: Simplicity, Harmony, and Wit................................. 16

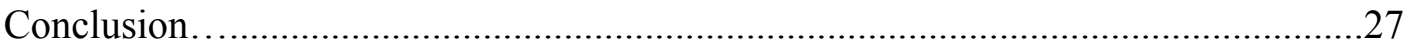

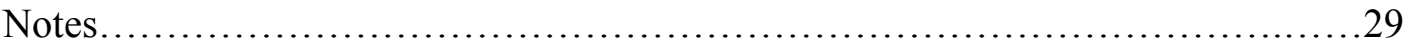






\section{Introduction}

Modern Chinese design is made up of distinct periods. It started in Shanghai in the 1920s and the 1930s. It developed from the 1950s to the 1970s in Hong Kong. And it made strides and flourished in Mainland China since the start of the Open Door Policy in 1979. Modern Chinese design is a cross-cultural design, which is characterized by combining Chinese cultural elements with Western design concepts and art styles.

I was educated both in China and America. My intercultural experiences and knowledge base make me think and design in a cross-cultural way. Especially when I selected an intercultural topic "ABC" (Americanborn Chinese) as the point of my thesis, the crosscultural creative pattern has become more attractive, and suitable for me to express myself personally. Moreover, my target audiences are American-born Chinese and their families, as well as some Americans with prejudices and racial discrimination. Thus, it is meaningful for me to solve a cross-cultural problem for audiences with cross-cultural backgrounds using a crosscultural design method. 


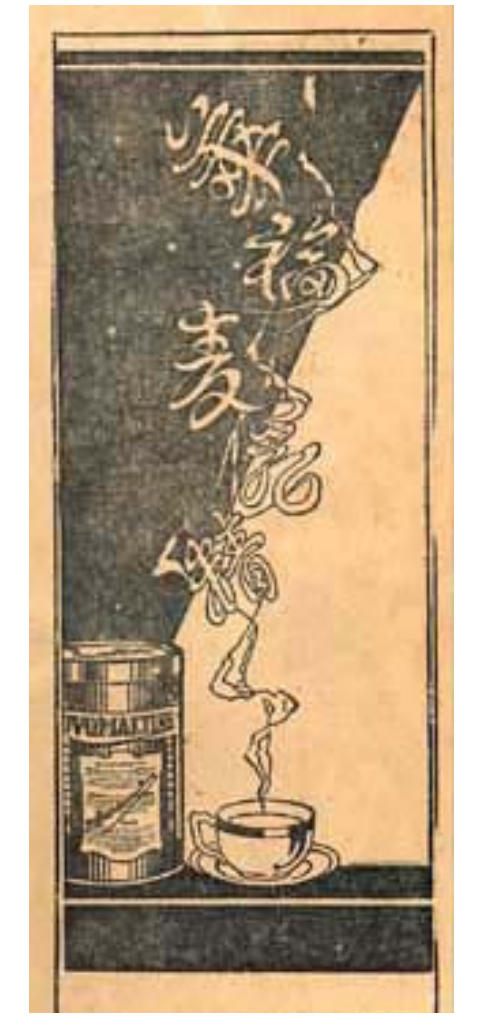

Fig. 1



Fig. 2

\section{Shanghai Style: Origin of Modern Chinese Design}

Modern Chinese design is a combination of traditional arts and crafts with Western influences. The 1920s and 1930s saw prominent examples of Modern Chinese design in Shanghai. During this period, a lot of design works produced in Shanghai reflected foreign influence. On one hand, the numerous foreign concession zones in the metropolitan city brought Western art style to the local life; on the other hand, the artists who were trained in Japan and Europe absorbed the inspiration of Western modern art and created new graphic works. In an advertisement for Ovaltine, Chinese written characters not only convey the product name, but also work as part of steam from a hot cup (Fig. 1). This change comes from the influence of Western modern art as shown in Fig. 2, where artists changed typography to concrete and expressive visual form to relate poetic content in Futurist poetry. Western design styles enriched the expressive vocabulary of Chinese traditional arts and crafts and speeded up the development of Chinese design. However, Modern Chinese design does not totally copy Western design theory and principles. 
Rather, it mixes West and East together, producing a new combination. As Minick and Jiao note, "coming to a culture with such a strong decorative heritage, the geometric and patterned compositions of art deco only succeeded in fueling further the renewed interests in China's own past [1]." They refer to the "masterful synthesis" characterizing Chinese design works at this time.

Shanghai style was the beginning of Modern Chinese design, which was stopped by the Second World War. After 1949, commercial graphic design was not allowed in China. Shanghai would not get the chance to continue its commercial design. However, the Shanghai spirit of commercial design had already rooted in Hong Kong after the war. 


\section{Hong Kong Period: Three Swordsmen}

The political policy and economic market provided a steady environment for Modern Chinese Design to develop in Hong Kong after the Second World War. American companies preferred their own graphic designers from overseas, challenging local Chinese designers to change their design styles to match American companies' requirements. "This transition was significant to the history of Hong Kong design, because it brought Western design theory and principles directly into contact with Chinese culture [2]." In this period, there were three important graphic designers who acted as 'exponents of an 'East/West' aesthetic that characterized Hong Kong design for the rest of the century [3]." They were Henry Steiner, Kan Tai-Keung, and Alan Chan.

Modern Chinese design benefited from the influx of American designers, and Henry Steiner was the most influential. As a student of Paul Rand's at Yale, he learned the two important design principles, "the primacy of concept" and the use of contrast to "give life" to a design [4]. Henry Steiner applied these two 


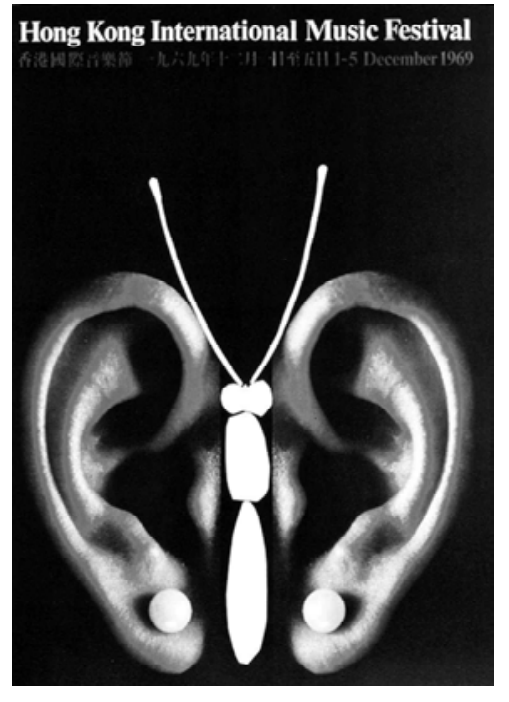

Fig. 3 principles into Chinese context, establishing a new principle of cross-cultural design. In his practice, he usually incorporated Chinese cultural symbols and characters into his Western design concepts and forms, giving design a wit and a life. In 1969, he designed a poster for the Hong Kong International Music Festival, in which he made two human ears working as the wings of a butterfly. He added two pearl earrings as symbolic references, indicating the festival held in Hong Kong, the "Pearl of the Orient", which is not strange to Chinese audiences (Fig. 3). In this simple poster, a lot of interesting information was addressed, such as music, ears, earrings, pearls, a butterfly, and Hong Kong, to attract audiences' attention and enrich their reading experiences. Henry Steiner blended his Western design concept with Eastern culture, inspiring and encouraging local Chinese designers to think and design in an international standard, and two pioneers were Kan TaiKeung and Alan Chan.

When Henry Steiner brought Western advanced design concepts and principles to Hong Kong and provoked 




Fig. 4 local Chinese designers to mix them with Eastern culture to experiment a new hybridized Chinese design style, some local designers went to extremes to simply copy and follow Western style, ignoring the specific context in Hong Kong. Even Kan Tai-Keung's early 1970s works lacked Chinese elements. Kan Tai-Keung started to employ Chinese elements in his designs in the mid1970s. In a poster for a design class (Fig. 4), he integrated Chinese written characters with constructed grid borrowed from the "International Typographic Style." He emphasized Chinese culture and thought that



Fig. 5 "research and study of our own traditional culture is the key to establishing a significant graphic design style, thus enabling us to take part in world design activity and make a worthwhile contemporary contribution [5].”

Another locally trained designer was Alan Chan. His understanding and interpretation of Chinese traditional culture won him a big reputation in Hong Kong since the 1980s. In his poster Hello Hong Kong (Fig. 5), he used modern computer pixel imaging and Chinese traditional brush stroke to modify the Chinese traditional dragon 
image, creating a combination West/East, ancient/modern image.

Designers in Hong Kong were not only the practitioners of cross-cultural graphic design, but also the educators and communicators of Modern Chinese design. Starting in the late 1970s, exchange activities happened between Hong Kong and mainland China and Taiwan, as well as Macau, resulting in the dawn of graphic design in China. 


\section{8: The Waken Lion}

When China's government announced its Open Door Policy in 1978, mainland China had been cut off from the outside world for almost three decades. The Great Cultural Revolution (1966-1976) made China immerse isolation and self-analysis. Political event played the main role in people's daily life, and science as well as art became a desert. "This was a dark period for intellectuals and the creative community, as it meant subordinating self-expression in all of the arts to the needs of the class struggle [6]." Graphic design could not find itself in commercial art activities except in the service of communist party propaganda. In such circumstances, Shanghai style was not maintained, rather than being developed. Modern Chinese Design style was gone with the wind.

It was the Open Door Policy that provided an opportunity for international exchange activities to take place between mainland China and outside world. Hong Kong designers introduced the latest international design trends into Mainland China through lectures, 
organizations' visits, and exhibitions in the late 1970s and early 1980s. Those activities brought creative and conceptual thinking into the old Chinese design education system, which was "based on a skill-training curriculum exported from the 1960s Russian model [7]." Young Chinese designers were inspired and influenced by the designers from Hong Kong. Some of them, such as Wang $\mathrm{Xu}$ and Wang Yue-fei, later became graphic design pioneers in mainland China. 


\section{Thematic Poster: Garden of Mind}

In the mid-1980s, due to the increasingly relaxed

political situation, thematic poster exhibitions were

initiated in Taiwan. Such non-commercial events

provided designers a free space to express individual

emotions and creative potential. When the trend spread

to mainland China, designers finally found an outlet to

demonstrate their graphic design talents. They didn't

need to worry about a lack of commercial markets, and

they also didn't need to see clients' long faces. Freedom

allowed them to create diversification. Till the mid-

1990s, thematic poster design improved quickly,

preparing for Chinese designers to enter the international

design community successfully.

Contemporary designer Wang Xu was educated in

China. His works were deeply marked with Chinese

cultural heritage. He believes in Taoist philosophies that

"propose that man return to a simple, unsophisticated life

and place himself in an amicable environment [8]." He

stresses the use of negative space to create simple and

clean styles that have won him much fame throughout

the design world. In 1995, Wang Xu was invited to the 
thematic poster exhibition in Taiwan under the theme

"Written Chinese Characters." He tried to reinterpret the

Chinese ideogram "claw" in an even more concrete way.

He used the object image a chicken foot to replace the



character (Fig. 6). He revealed the origin of the

character and he made that character transcend the

Chinese language limitations, reaching a new dimension

to use human language (image) to explain and

communicate Chinese culture.

Fig. 6

In the late 1990s, Chinese graphic designers gained more visibility and earned awards in various international poster competitions. One of these is Chen Fang. Chen

Fang explored and interpreted Chinese cultural elements and related them to Western influences. As Robert Treadway said "designer Chen Fang emerged with a bent for graphic expression that mixes traditions of his homeland with a modern, global outlook [9]." Chen Fang emphasized the importance of exchange with the outside world, trying to become a part of the global design community. His opinion is that "a good design should go beyond a cultural boundary [10]." His famous 
poster Victory (Fig. 7) won him first place at the Festival

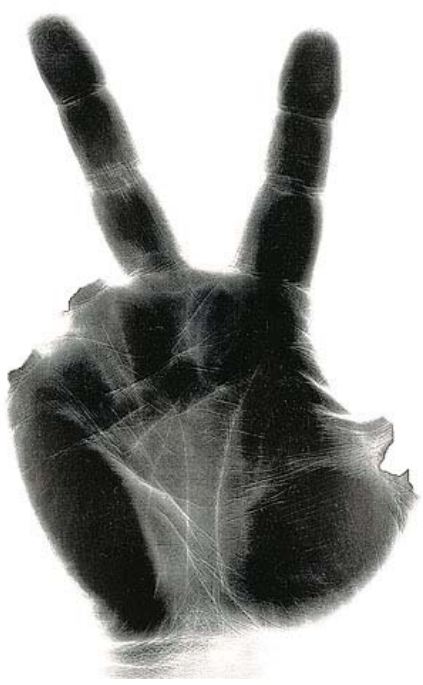

Fig. 7
d'Affiches de Chaumont, France, in 1998, and the

Colorado International Invitational Poster Exhibition in 1999. In this poster, Chen Fang used his hand to form a Western victory symbol "V". The missing fingers imply the relationship between the sacrifice and victory. He did not stop with interpreting the Western victory symbol in a meaningful way. He continued to add Chinese cultural elements to push this poster to a dimension of "mystery and precision [11]". He kept his hand lines clearly visible. According to Chinese folklore, people can forecast fate based on the lines' shape and direction. Thus, Western culture and Eastern culture are merged rationally. 
ABC Issue: The Confusion as Marginal Men My daughter was born last June. Since then, Americanborn Chinese $(\mathrm{ABC})$ has become an interesting topic in my family. $\mathrm{ABC}$ is a special group. Their parents come from China. They are born and growing up in America. As the first generation Americans, they are educated both in Chinese (at home) and American (in society) contexts. The different cultures between East and West bring them a lot of confusion. As May Tung said, "Confusion is inevitable when one lives in the cross section of East and West. Chinese Americans must sort out the contributing factors from sides in the selfidentification process [12]."

Basically, ABC issues come from the physical distinctions upon which racial definitions are based. $\mathrm{ABC}$ 's yellow color is a major barrier to stop them from entering American mainstream. However, the white skin of immigrants from Europe "gave them the potential eventually to become invisible, to meld into the mainstream [13]." ABC's parents suffer a lot due to their color and language. They are afraid of being 
discriminated against. They don't want this to happen to their children. When they couldn't change racial stigma, they are strict with their children about study. They want them to be straight-A students, since they think that education can make their lives easier in part. However, education can not save them from their color. Even after they entered the mainstream, discrimination still haunts them. That is the reason why $\mathrm{ABC}$ is called Honorary White as a banana by their white companions. That is the reason why when Michelle Kwan lost her medal to her European American friend in the Winter Olympic Games in 1998, the MSNBC titled the news as "American Beats Out Kwan." When ABC does not benefit from straightAs, some of them have to hate their skin color. They think they are white, or they want to change their skin tone from yellow to white. On the other hand, some $\mathrm{ABC}$ long for freedom and equality, rejecting discrimination and assimilation. They are "never ashamed of being Chinese" and they are "proud to be linked to a great civilization" [14]. They want to integrate into the mainstream without losing their Chinese identity. 
$\mathrm{ABC}$ is a very complicated issue, it is associated with $\mathrm{ABC}$, their parents, and their surroundings. When I did research about $\mathrm{ABC}$, I found their situations are very complicated. In reality, they have to face discrimination, assimilation, isolation, prejudice, insularity, and internalized inferiority. In their dreams, they thirst for integration, adaptation, equality, and keeping their own identities. They are confused by their treatment in a country bragging about freedom and equality. There are a lot of ways to solve this problem. And mine is to educate my audiences with graphic communication. 
My Solution: Simplicity, Harmony, and Wit

What is the design philosophy of Chinese designers?

Minick and Jiao point out "Chinese design traditionally emphasizes the absence of form in an attempt to stress the spirit" and "the concept and harmony" and the "yin and yang principle" [15]. Chinese designers follow these heritages and develop specific simple and clear design styles. Chinese designers don't stop with their own obvious traditional and contemporary elements. Their open minds lead them to an even broader outside world. Serge Serov says, "Chinese design succeeds also thanks to its sensitivity to different kinds of breezes and winds, to its openness and readiness for different cultural inflows [16]." Reviewing the examples mentioned above, it is not hard to find these characteristics in Chinese designers' works.

As a Chinese designer educated both in Eastern and Western cultures, it is even more impossible for me to think and design without multicultural influences. First of all, I pursue simple, airy, harmonious style, which comes from Taoist philosophy and Yin Yang principle. 
There are many Chinese designers claiming and practicing this style. Hong Kong designer Kan TaiKeung was a practitioner of modern Chinese shuimo painting. He applied Chinese traditional painting skills into to his modern design, forming his simple, fresh, elegant styles. He often uses Chinese high art objects, brush stokes, and black, white, and red colors in his design. His business card design is good evidence to summarize his continuous style (Fig. 8). He used white Fig. 8



Fig. 9 color as the background; he put Chinese brush stroke, brush stand, and a Chinese watercolor brush together to organize the structure. He used black and red colors for his name and address. All of these make the card simple, clean, clear, and full of a sense of culture. In another of his earlier works, a poster (Fig. 9) for an exhibition Shui Mo: the New Spirit of Chinese Tradition in 1985, he treated the elements and colors in a similar way. He used white color as background, on which black brush stroke, Chinese painting palette, and red paint were organized to form his simple signature style. In my poster series, I also tried to experiment with this simple, clean, and elegant style. For example, I limited the color in all the 


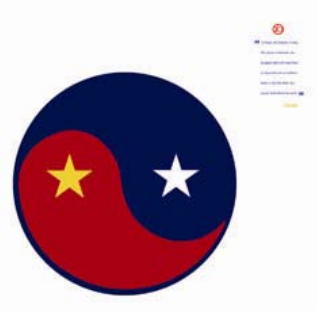

Fig. 10



Fig. 13

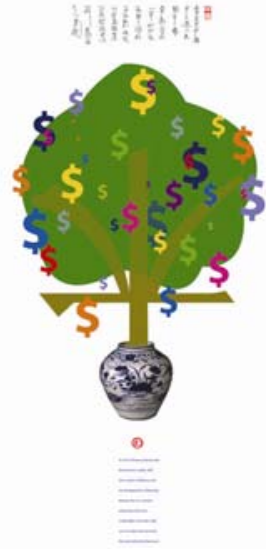

Fig. 11

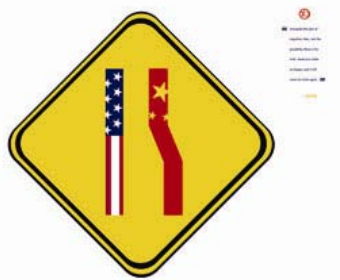

Fig. 12

posters. In Yin Yang (Fig. 10), Made in China (Fig. 11), and Merge (Fig. 12), I used white as the background color to achieve one of my goals: simplicity, cleanness, quietness, and harmony. I am familiar with Chinese calligraphy. I benefited from its "thinking white as black" layout rule to balance negative space with positive space, reaching harmonious effect. For example, in my cover poster American-born Chinese (Fig. 13), I used big negative space to form " $\mathrm{A}$ ", creating scale, contrast, and balance. 


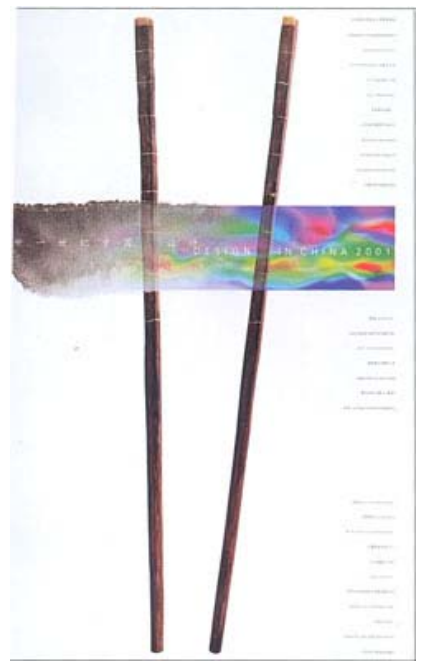

Fig. 14

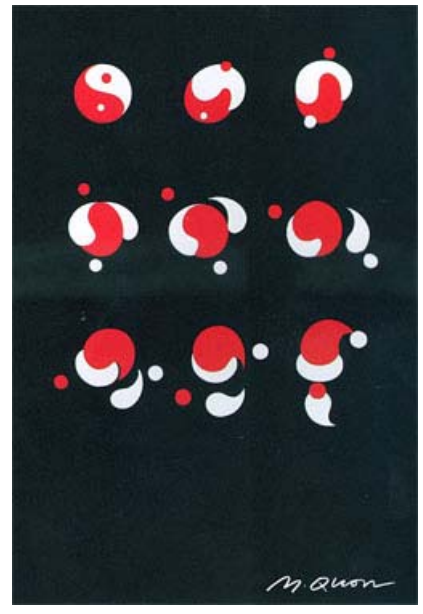

Fig. 15
Secondly, ABC is the product of two different cultures. The $\mathrm{ABC}$ issue is about the impact of East and West. So using cross-cultural design to solve a cross-cultural problem is an effective and efficient method. Kan TaiKeung is also a good practitioner of this point. In the poster Design in China 2001 (Fig. 14), he used a pair of chopsticks to replace the two similar vertical strokes in a Chinese character which means twenty-one. In doing so, a lot of audiences who don't know Chinese could guess the location of the event with the help of the strong symbol (chopsticks) of China. Symbolic language is broadly applied as an important tool in cross-culture communication. When Mike Quon designed his holiday greeting card (Fig. 15), he benefited from his double culture background. He connected two totally different symbols the East "Yin Yang" and the West "Santa Claus" together through the course of seven changes of the Yin Yang symbol to create a happy and active holiday climate and to address his American-Chinese identity on the other hand. Two different mixed symbols make more audiences involved in the happiness of the holiday celebration. In my series posters, I tried to put two different visual symbols together to express my 
ideas to make sure my target audiences from two

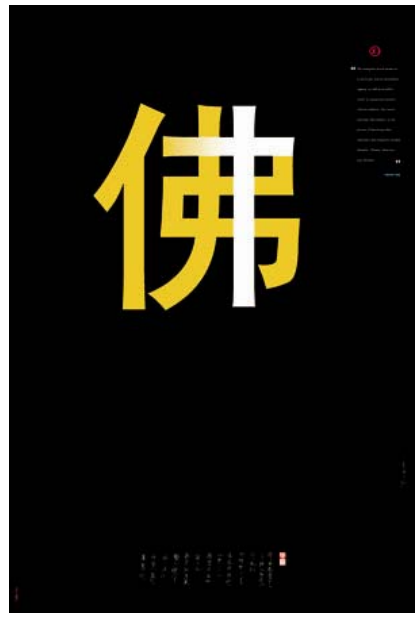

Fig. 16

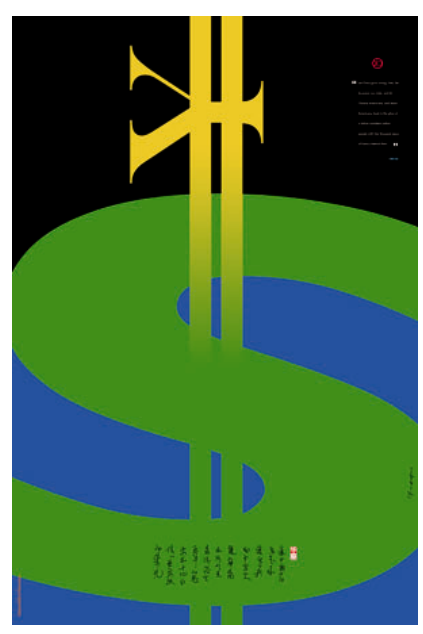

Fig. 17 different cultures better understand what I am talking about. For example, in Buddha and God (Fig. 16), I borrowed two strokes from the Chinese written character Buddha to form a cross symbol through which to tell the story about the religion idea in $\mathrm{ABC}$ family. In Yin Yang (Fig. 10), I made small modifications to the original Yin Yang symbol. I used colors and stars from Chinese and American flags to replace the colors (black and white) and the circles respectively, suggesting the East and the West should live in harmony to build a good environment for $\mathrm{ABC}$ to live in. In American Dollar and Chinese Yuan (Fig. 17), I juxtaposed the signs of dollar and Chinese Yuan, forecasting the growing future of Chinese Yuan, and reminding audiences that China is becoming stronger and stronger, from which $\mathrm{ABC}$ will benefit.

Thirdly, I don't like that kind of simplicity and cleanness without connotation. I also don't want to simply put several different visual symbols together to force audiences to accept my solution. I try to create some 
witty ideas to attract their attention and interests. What is a witty idea?

The two elements - 'the familiar' and 'the play'are responsible for the two main emotions experienced by someone 'getting' a witty idea recognition and surprise. These two main characteristics of wit provide a kind of matrix of success. If a witty solution involves a great deal of recognition but little surprise, the solution will be obvious and weak, if, on the other hand, the solution involves a great deal of surprise but little recognition, it will be baffling, enigmatic and impenetrable to most people, prompting anxiety and a feeling of failure. If the solution is low on both recognition and surprise - total failure. If it is high on both - if it combines great familiarity with a big surprise - the solution will be a success, a hit [17].

I love witty ideas. I like to encode and decode witty ideas. Witty ideas are light in the dark. They grab audiences' eyes, they attract them to approach and 




Fig. 18

decode. They help them to recall their deep memories and remind them to take action.

There are many types of wit. "Juxtaposition, the art of

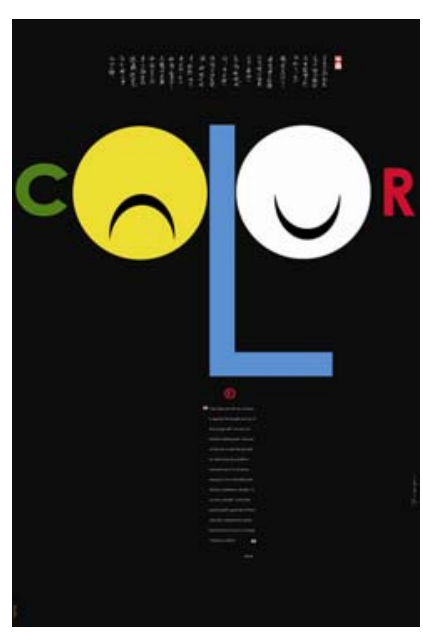

Fig. 19 surprising contrasts, is at the core of wit [18]." Pairing

usually put two differences together, revealing the hidden myths between unrelated. Designer Chen Fang used pairs in his poster series We Are One (Fig.18). He examined racial and ethnic issues by juxtaposing different racial faces, leaves, masks, and animals' faces, expressing "let's love each other; we are all travelers of long distance, towards the same destination [18]." I used pairs in my poster Color Face (Fig. 19), I juxtapose a happy face and a sad face to assert the fact that different 
skins matter in America. Pairing creates contrast and comparison, resulting in surprise and comprehension.

Substitution is a popular type of wit.

This is a classic two-in-one technique. The designer substitutes one element within the image to introduce the second idea. Success depends on introducing a rogue element, which is visually similar but remote in meaning (and also accurate terms of message). In the temporary fusion of two normally incompatible components, the designer achieves the essence of wit, both recognition and surprise [19].

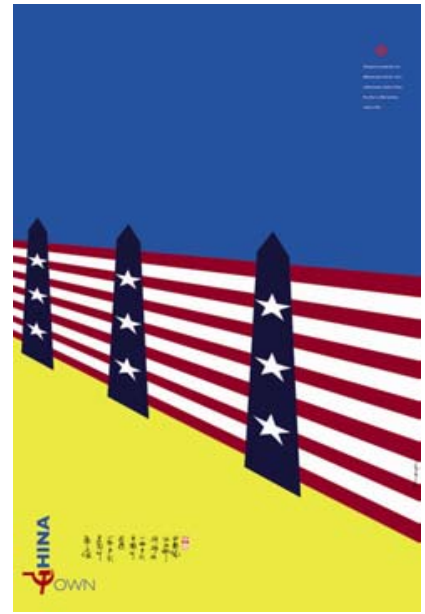

Fig. 20
In China Town (Fig. 20), a normal wood fence is replaced by modified symbols of the American flag and the Washington Monument, representing racial discrimination and exclusion. Another type of wit is also used in this poster, coincidence route, where designers use a given element to carry extra information. The sickle and the hammer play two roles: the symbol of Communist Party flag and the initials of China-town. 
I used coincidence to create surprise out of the recognition. The juxtaposition of symbols of capitalist and communist in one poster enforces the meaning of impact, isolation, and conflict. In Buddha and God (Fig. 16), I also applied coincidence route. In the Chinese character of "Fe" (Buddha), two strokes are coincidently the same as the cross. I modified the strokes by changing the color and adding the gradient effect, building a connection between Buddha and God.

Sometimes, several types of wit are used in one design. For example, in Yin Yang (Fig. 10), I mixed pairs, substitution, and homage together. Juxtaposing flag

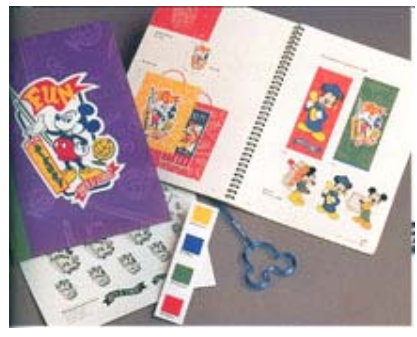

Fig. 21 colors, substituted circles and stars, and the existing Yin Yang symbol are compressed in this simple and profound design. Homage route is a design short-cut, through which designers graft their new messages onto the existing graphics. They borrowed the credits of old icons to serve their new ideas and to get instant understanding at the expense of half a communications job. John Sayles designed a back-to-school media kit for families in Asia (Fig. 21). He used Disney's Mickey 
Mouse, one of the most familiar cultural icons in the world, to convey his message, receiving an effective communication result. My poster Merge (Fig. 12) works in the same way. Based on the familiar traffic sign, I substitute the solid black lines for symbols of the American and Chinese flags, adding the new meaning to the old sign.

Some other types of wit I used in my series are metaphor



Fig. 22 and scale shift. In Self-Portrait (Fig. 22), I used massed lines to cover the face, implying that $\mathrm{ABC}$ need selfconfidence and to be accepted by mainstream. In Made in China (Fig. 11), I used a Chinese style pot to stand for my homeland and an upside-down Chinese written character "Tree" to stand for an abstract trunk. I put the tree into the pot to suggest the idea of "made in China". I hung a lot of dollar signs on the tree to plant a "Dollar Tree", telling the story that a lot of products in the United States come from China and emphasizing the dependant relationship of two countries, which makes ABC feel more comfortable in USA. 
The last type of wit I experimented with in the series is

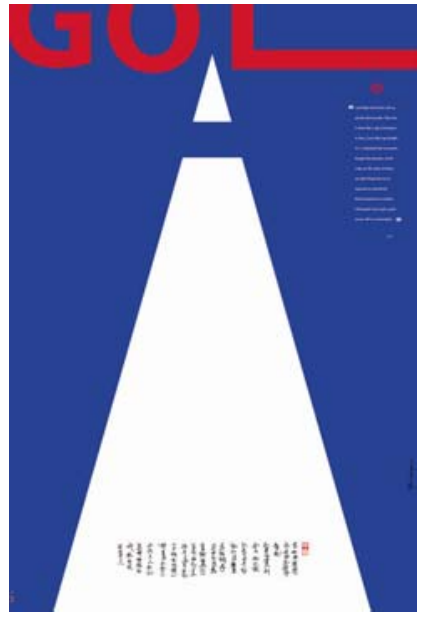

scale shift. In Goal-A (Fig. 23), I enlarged the "A" in the word "goal" to the extreme, making it work as the whole background of the poster to emphasize that the parents of ABCs always want them as straight-A students. The purpose of scaling is to disrupt people's expectation, to grab their eyes, and to rebuild their recognition with surprise.

Fig. 23 


\section{Conclusion}

Modern Chinese design is characterized with Taoist simplicity, cross-culture communication, and witty idea application. In my poster series, I experimented with all of these principles and methods. They help me to use communication graphics to solve my $\mathrm{ABC}$ problems in part. However, any rules are produced for solving specific problems. When something new happens, new methods are needed. ABC issues are new cases. To solve the problems, I need to face three different target audiences: $\mathrm{ABC}$, their parents, and Americans with prejudices. Based on their different backgrounds and experiences, I have to develop some new effective methods to achieve great understanding and communication. What is the most important characteristic of my audience? It is bilingual. To make sure my messages are conveyed and understood correctly, I need to find a way to direct them to read and think along the right direction. My method is that bilingual expressions serve bilingual audiences. Taoist style emphasizes simplicity and encourages artists to leave enough space for readers to imagine, develop, and invent. This is a good method for personal expression. 
However, when you get your audiences and try to help your audiences to solve their problems, you must limit and frame your topic in a correct way. There are one hundred different Hamlets in one hundred readers' minds. That is a fine art rule, but it is not working here. If you design something that can be read in many ways, then how will the audiences follow you, and what are your suggestions and directions? In my case, I used bilingual quotations from the books about $\mathrm{ABC}$ issues to help audiences follow what I am thinking and calling for. Bilingual quotation plus bilingual red signature seals and my Chinese calligraphy enrich the cross-culture communication and modern Chinese design. 


\section{Notes}

1. Minick, S., Jiao P. Chinese Graphic Design in the Twentiethh Century. London, Thames and Hudson (1990).

2. Wendy Siuyi Wong, Detachment and Unification: A Chinese Graphic Design History in Greater China Since 1979. Design Issues: Volume 17, Number 4 Autumn 2001, 53.

3. Wendy Siuyi Wong, In Search of a New Graphic Design Frontier in China: Establishing the "Chinese-ness" of International Style.

4. Wendy Siuyi Wong, Detachment and Unification: A Chinese Graphic Design History in Greater China Since 1979. Design Issues: Volume 17, Number 4 Autumn 2001, 53.

5. Robert L. Peters, No Sleeping Dragon: The Dawn of Graphic Design in China. Communication Arts, March/April 2004.

6. Robert L. Peters, No Sleeping Dragon: The Dawn of Graphic Design in China. Communication Arts, March/April 2004.

7. Lin Jianyang, On Design Education, Art and Design, Beijing: Art and Design Publishing House, June 2000, 29-34.

8. Robert L. Peters, No Sleeping Dragon: The Dawn of Graphic Design in China. Communication Arts, March/April 2004.

9. Robert Treadway, After the Revolution. Print, July/August 2003, 103.

10. Robert Treadway, After the Revolution. Print, July/August 2003, 107.

11. Robert Treadway, After the Revolution. Print, July/August 2003, 107. 
12. May Tung, Chinese American and Their Immigrant Parents, Binghamton, NY: The Haworth Clinical Practice Press, Inc. 25.

13. Nazli Kibria, Becoming Asian American. Baltimore and London, The Johns Hopkins University Press, 2002, 6.

14. Eric Liu, The Accidental Asian. New York, Random House, 1998.

15. Minick, S., Jiao P. Chinese Graphic Design in the Twentiethh Century. London, Thames and Hudson (1990).

16. Serge Serov, Area, Phaidon Press Inc, 2005, 392.

17. Beryl McAlhone, David Stuart, A Smile in the Mind, Phaidon Press Inc, 1998, 16.

18. Beryl McAlhone, David Stuart, A Smile in the Mind, Phaidon Press Inc, 1998, 38.

19. Robert Treadway, After the Revolution. Print, July/August 2003, 108.

20. Beryl McAlhone, David Stuart, A Smile in the Mind, Phaidon Press Inc, 1998, 42. 


\section{Bibliography}

Lin, Jianyang (2000, June). On Design Education, Art and Design (Beijing: Art and

Design), Publishing House, Beijing.

Liu, Eric (1998). The Accidental Asian. New York, Random House.

McAlhone, Beryl and Stuart, David (1998). A Smile in the Mind, New York: Phaidon

Press Inc.

Peters, Robert L. (2004, March/April). No Sleeping Dragon: The Dawn of Graphic

Design in China. Communication Arts.

Minick, S. and Jiao P. (1990). Chinese Graphic Design in the Twentieth Century, London: Thames and Hudson.

Serov, Serge (2005). Area, Phaidon Press Inc. p. 392.

Treadway, Robert (2003, July/August). After the Revolution. Print pp. 102-109.

Tung, May (2000). Chinese American and Their Immigrant Parents, Binghamton, NY:

The Haworth Clinical Practice Press, Inc.

Wong, Siuyi Wendy (2001, Autumn), Detachment and Unification: A Chinese Graphic

Design History in Greater China Since 1979, Design Issues: pp 51-71.

Wong, Siuyi, Wendy, In Search of a New Graphic Design Frontier in China:

Establishing the "Chinese-ness" of International Style. 